THURSDAY, MARCH 22, 1888.

\section{THE REVENUE METHOD OF ESTIMATING AND CHARGING THE DUTY ON SPIRITS.}

THIS subject has attracted some notice since Sir Henry Roscoe put a question to the Chancellor of the Exchequer the other night in the House of Commons, as to whether his attention had been called to the fact that, owing to the present faulty system of charging the duty on spirits, a loss to the Revenue of from $£ 60,000$ to $£ 80$, ooo per annum did not occur, without any corresponding benefit to the trader, and whether he would appoint a Departmental Committee to inquire into an improved system of estimating the percentage of spirit, as proposed by Dr. Derham. To this the Chancellor replied that the above estimated loss was based on an erroneous assumption, and that the introduction of the suggested system would be attended with difficulties comparable with those which would accrue to the substitution of the decimal for the present system of coinage. The grounds of these objections could not of course be given in answer to a question, and therefore the public are not yet in a position to judge how far the Revenue Departments can make them good. The statements of Dr. Derham are, however, perfectly plain, and demand plain answers.

They are (I) That the essential defect of the present system is well known and acknowledged by the Inland Revenue Department.

(2) That this defect depends on the erroneous assumption made by Sikes in constructing his tables that any given quantity of spirit does not alter in bulk or in strength with variations of temperature from the normal of $5 \mathrm{I}^{\circ} \mathrm{F}$.

(3) That the only argument which can be advanced in defence of the present system is that deficiencies at temperatures below $5 \mathrm{I}^{\circ} \mathrm{F}$. are compensated by overestimates above $5 \mathrm{I}^{\circ} \mathrm{F}$., so that on the whole the Revenue neither gains nor loses.

(4) That on the contrary it is a fact that at least fivesixths of the spirits paying duty are taken out of bond during the nine cooler months of the year when the temperatures in warehouses range from $51^{\circ} \mathrm{F}$. downwards, so that in the case of these spirits a constant loss accrues to the Revenue, and also to the trader from under-estima tion of his stock, which he must dispose of at that estimate. Whilst in the summer months, owing to the construction of warehouses, evaporation of spirits, \&c., the temperature of the spirits does not often exceed $5 \mathrm{I}^{\circ} \mathrm{F}$., so that there is but a slight compensating gain to the Revenue from that source.

(5) That the objections to the present plan can be entirely removed by adopting the suggested system, which, without altering the standard of measure-the proof gallon-without introducing any change in the notation of over- and under-proof, or any alteration calculated to confuse the trader, substitutes tables founded on a correct principle instead of an erroneous one, a scientific and exact for an unscientific and inexact instrument, which not only will facilitate the work of the Government officials, but will give correct results at all temperatures.

In consequence of the "non possumus" reply of the Vor. XxxvII.-No. 960.
Chancellor, Sir H. Roscoe gave notice that he should move for a return of the number of proof gallons taken out of duty free warehouses for consumption last year. specifying the number of proof gallons at each degree of temperature when the account was taken for payment of duty ; all spirits taken out for methylation, exportation, ships' stores, and removal to other warehouses, which do not pay duty, and which may have recently been distilled, being excluded. Such a return would either confirm or disprove Dr. Derham's contention, and there seems no reason why such a return should not readily be obtainable. It appears to us that the comparison of the introduction of the decimal coinage made use of by Mr. Goschen was an unfortunate one. The introduction of the decimal coinage would obviously occasion a great amount of confusion and perplexity, for a time at least, and would in the end only substitute one correct and convenient system for another equally correct though less convenient. The adoption of the improved system of charging duty on spirits would occasion, on the contrary, no material change, none likely to cause confusion or perplexity, but would replace an incorrect and inconvenient system by one at once correct and more convenient. The Chancellor moreover hinted that the vested interests of the trade in the property of the present instruments must be safeguarded. If the new and correct tables became legalized and were adopted, Sikes's hydrometer could equally well continue to be used, or any instrument can be employed which furnishes specific gravities. $\mathrm{Mr}$. Goschen also stated that Dr. Derham's instrument is too delicate for ordinary use. This appears to us to be the weakest part of his argument. The ball in the new instrument, the most vulnerable part of the hydrometer, happens to be of the same size and strength as that in the ordinary Revenue instrument. It is true that a somewhat different method of attaching the poises is adopted, but this is a mere detail, and more a question of taste and opinion than of principle, and it is certain that the form can, if desirable, be made so as to be indistinguishable from Sikes's instrument, for the characteristic feature of the new system is to be found in the bulks and specific gravities of the poises, and not in the shape or size of the stem or bulb.

The Revenue authorities can scarcely, we imagine, fail to admit that certain defects in Sikes's system exist, for these can be demonstrated by reference to Sikes's own tables. Hence we incline to the belief that the erroneous assumption to which the Chancellor referred consists in taking for granted that there is a general correspondence between the temperatures of warehouses and that of the mean shade temperature of the country, for this is the assumption made by Dr. Derham. The returns which have been asked for will decide this point. But meanwhile it may be of interest to see how the large figures of from $£ 60,000$ to $£ 80,000$ per annum have been obtained. The Customs and Excise deal annually with some forty million gallons of proof spirit or their equivalent, which for the most part lie for a longer or a shorter time in warehouse. If we assume that the average strength of the spirit when removed from warehouse for consumption is 25 overproof, then thirty-two million gallons by measure are equivalent to the forty million gallons upon which the duty is charged, so that, if the rate of removal be 
constant, 2,700,000 gallons by measure at 25 overproof are removed each month from bond. Now, taking the mean shade temperatures for the months from November 1886 to April 1887 , it appears that, owing to the contraction in these $2,700,000$ gallons per month, no less a quantity than 97,268 gallons of 25 overproof or of 121,586 gallons of proof spirit for the six months would accrue in the estimation as now carried on, and the duty on this amounts to $£ 61,000$, now lost to the Revenue.

It is true that probably these shade temperatures do not exactly represent the temperatures of the warehouse, which will be more equable, but then the contents of a warehouse if they lose their heat slowly also regain it slowly, and the low temperature contracted during a long and severe winter is perpetuated for a long period throughout the year; so that in all probability the average temperature of the bonded spirit is below $5 \mathrm{I}^{\circ}$ not only during six but during nine months of the year, and assuming that the mean temperature did not exceed $47^{\circ}$ during these extra three months, the additional loss to the Revenue would amount to $£$ Io,ooo.

The foregoing statements have been published for some time, and have not been confuted except in the usual official Parliamentary style. This, we urge, is insufficient. What the public wants to know, and has a right to learn, is, what, if the Revenue authorities dispute these assertions, are their grounds for so doing? Should this information not be forthcoming, the opinion will gain ground that another Government Department is trying hard "how not to do it."

\section{PRESTWICH'S "GEOLOGY."}

Geology: Chemical, Physical, and Stratigraphical. By Joseph Prestwich, M.A., F.R.S., F.G.S., Correspondent of the Institute of France, Professor of Geology in the University of Oxford. In Two Volumes. Vol. II. Stratigraphical and Physical. (Oxford: Clarendon Press, I888.)

$\mathrm{T}$ is just two years ago that we were called upon to notice the first volume of this important treatise ; and the author of it has now signalized the completion of his labours at Oxford by giving to the world the second and concluding volume of the work. Its publication has long been eagerly looked forward to, and now that the book is before us, we may safely assert that it more than justifies the high expectations which have been formed concerning it ; and we confidently predict that it will add to the already high reputation of the veteran geologist to whom we are indebted for it.

In reading the first chapter of the book, everyone must be struck by the fact that a distinct advance has been made in the mode of treatment of the great problems of stratigraphical geology. Speaking of the "order of succession" and "the breaks in continuity" in the series of stratified rocks, Prof. Prestwich writes:-

"The great time-divisions are of almost universal application ; but the smaller 'breaks in continuity,' which are of frequent occurrence in all areas, are subject to constant differences of extent and value ; consequently, in filling up the details of the several geographical areas, each one is found to have its own local stamp, and possesses its own special terms, some knowledge of which is as essential to the geologist as is the language of a country to the traveller, if he would pass through it with profit."

The author then proceeds to show how impossible is any universal scheme of geological classification, and to discuss the question, first raised by Edward Forbes and Prof. Huxley, as to how far geological equivalence is to be regarded as being identical with actual synchronism.

$\mathrm{He}$ insists that, in distant areas, strata cannot be corre lated by identical species, but only by the presence of the same characteristic genera, and he fully admits the effects of migration of forms of life from one region to another in causing strata of different ages to present very similar faunas or floras. Such considerations as these, the author argues, must always prevent us from regarding the series of formations as being strictly contemporaneous in distant areas, or the breaks between them as being universal ones.

Prof. Prestwich points out some of the difficulties confronting geologists, in the following suggestive passage :- -

"In Western North America the great break so conspicuous between the Cretaceous and Tertiary series does not exist, and there are passage beds having characters of the two periods in common. In a similar way the Carboniferous strata in America pass gradually into the Permian, without the unconformity which exists here. In India the Gondwána system forms a consecutive series from the base of the Permian to the top of the Jurassic strata. In New Zealand, again, no marked line can be drawn between the Cretaceous and Tertiary series, the Upper Cretaceous and Lower Eocene forming unbroken and continuous series."

He then proceeds to give not one table of classification for the sedimentary rocks, but six different ones, adapted respectively to Europe, India, North America, Australia, New Zealand, and South Africa. And having thus at the very outset shown what are the obstacles in the way of the exact correlation of distant deposits, and established a philosophical basis of classification for strata, he takes up the consideration in succession of the several great geological systems; he selects the method of beginning with the oldest, and passing upwards in the scale, candidly admitting, however, that the opposite plan is not without its merits and advantages.

The account given in successive chapters of the several formations, their typical development in this country, the groups of fossils by which they are distinguished, and their chief foreign representatives, is eminently clear and readable. This merit is the more conspicuous from the circumstance that the mass of detailed information to be selected from and arranged in writing a work on stratigraphical geology is so enormous and bewildering, that such works are very apt to suffer in their style, and to become heavy and encyclopædic in character. But Prof. Prestwich has admirably avoided this danger.

The author does not waste any time in discussing barren questions of nomenclature. In the case of the three systems of the older Palæozoic, he follows the common custom of calling the oldest "Cambrian," the second "Lower Silurian," and the third "Upper Silurian"; though pointing out in a footnote the significance of the term "Ordovician."

Very striking features in the book are the chapters in which are summed up the characteristics of the faunas 